\title{
EL E-COMMERCE Y LA LEGISLACIÓN EN AMÉRICA LATINA Y EL PERÚ
}

\section{E-COMMERCE AND LEGISLATION IN LATIN AMERICA AND PERU}

Aldrudover Blas Rivera*

* Doctorando en Derecho y Ciencias Políticas por la Universidad Nacional Mayor de San Marcos (UNMSM) ; Doctorando en Gestión Estratégica por el Consorcio de Universidades (PUCP- ULIMA, UP, UPCH); Máster en Management International Trilingue (Université Paris XII) ; Maîtrise en Administration et Échanges Internationaux (Université Paris XII) ; Abogado por la Universidad Nacional Federico Villarreal (UNFV) y Licenciado en Administración de Negocios Internacionales (UNMSM). Correo electrónico: Aldrudoverblas@gmail.com Dirección: Calle La Habana 111 - Edificio 3A- Dpto. 301 - Condominio Alameda de la Molina - La Molina- Lima ( Altura de la central del BCP) Teléfono: 987983184 / 01 6966595

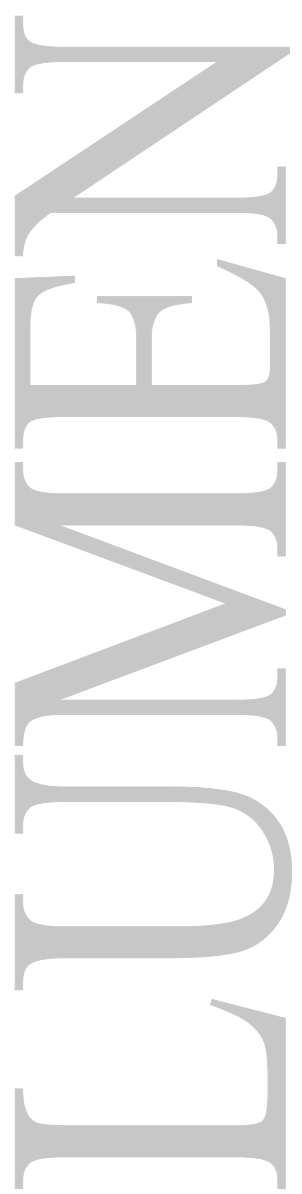




\title{
EL E-COMMERCE Y LA LEGISLACIÓN EN AMÉRICA LATINA Y EL PERÚ
}

\author{
E-COMMERCE AND LEGISLATION \\ IN LATIN AMERICA AND PERU
}

Aldrudover Blas Rivera

\begin{abstract}
RESUMEN:
La evolución del Comercio Electrónico, en el mundo y América Latina en particular, ha permitido el incremento del intercambio entre los países; en el mismo sentido, los países deben regular dicho intercambio a través de un conjunto de normas que garanticen que el comercio se desarrolla con seguridad jurídica. En dicho contexto, la Ciberlegislación es el instrumento jurídico que regula distintos aspectos del comercio electrónico, además de promover el comercio nacional y transfronterizo de entidades gubernamentales, empresas y/o personas con actividades empresariales, consumidores y/o ciudadanos, en el contexto dinámico de los mercados.
\end{abstract}

\section{PALABRAS CLAVES:}

Comercio Electrónico - Ciberlegislación.

\section{ABSTRACT:}

The E-Commerce evolution, in the world and specially in Latin America, has allowed the increase of exchange between countries; In the same way, countries must regulate this exchange through a set of rules that guarantee that trade is carried out with legal certainty. In this context, Cyberlegislation is the legal instrument that regulates differents aspects of E- commerce. In addition, to promoting national and crossborder commerce of government entities, companies and people with business activities, consumers and citizens, in the dynamic context of the markets

\section{KEY WORDS:}

E- Commerce - Cyberlegislation

\section{INTRODUCCIÓN}

\section{Economía Digital}

La economía digital, entendida como la difusión de los negocios a través del uso de tecnologías, productos y servicios (Brennen \& Kreiss, 2014), ha tenido un vertiginoso desarrollo y se enfoca en tres grandes aspectos:

a) innovaciones fundamentales (Semiconductores, procesadores), Tecnologías centrales (Computadoras, dispositivos de telecomunicaciones) e Infraestructura habilitadora (Internet y redes tele comunicacionales). b)Tecnología digital y de la información como las plataformas digitales, aplicaciones de celulares y servicios de pago. c)Sectores de digitalización, los cuales incluyen los productos digitales servicios, entre ellos el comercio electrónico. (Conferencia de las Nacionales Unidas para el Comercio y el Desarrollo - UNCTAD, 2019 p.5). 


\section{Figura 1}

Representación de la economía digital

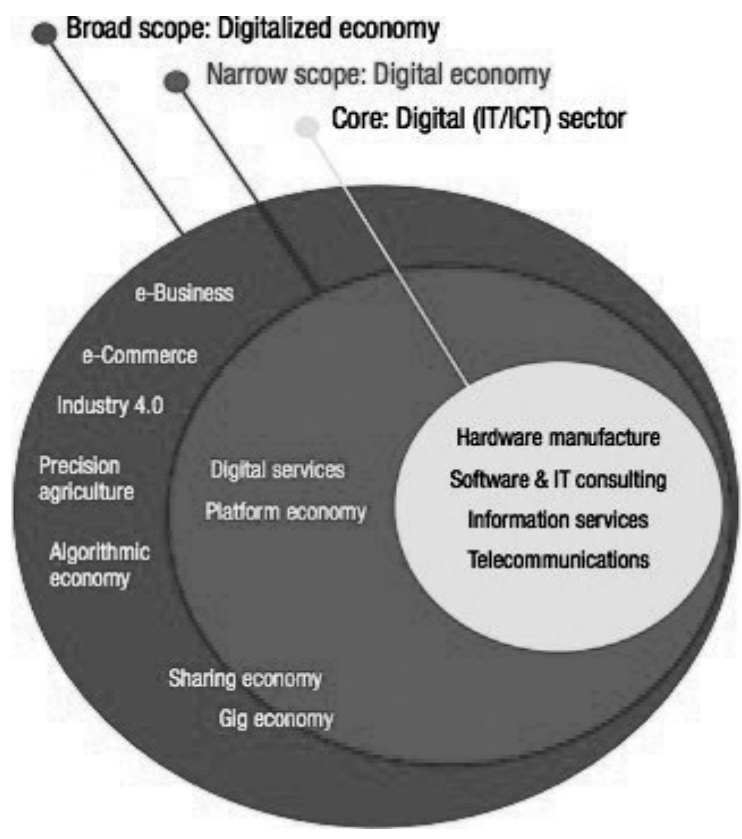

Nota.- El gráfico muestra la ubicación del e-commerce en la economía digital y lo que ella implica. Tomado de Bukht and Heeks, 2017 (P.13) por Digital Economy Report, 2019, UNCTAD.

\section{Comercio Electrónico o E-Commerce}

El E-commerce es el resultado de la compra y venta de bienes y servicios on line, el cual Incluye el uso de las plataformas y transacciones realizadas. Al respecto, podemos citar:

El comercio electrónico, comercio digital o e-commerce, se refiere a aquel tipo de transacción entre personas y empresas que involucra la compra, venta o intercambio de productos, bienes o servicios, que se desarrolla a través de redes informáticas, fundamentalmente internet, y cuyo sistema de pago es también electrónico, más usualmente mediante tarjetas de crédito. (Ordoñez Moran, Ordoñez Peña, \& Victor, 2016 p.7).

El comercio electrónico comprende las transacciones que se realizan (por ejemplo, las órdenes de compra que se emiten) a través de sistemas de redes informáticas que utilizan tecnologías de Internet y cuyos importes contractuales se capturan a través de dichos sistemas. En un sentido más amplio, "Internet" se sustituye por "sistemas de redes informáticas. (Organización para la Cooperación y el Desarrollo Económico - OCDE, 2019 p.18).

\section{Clasificación del Comercio Electrónico}

El E-commerce o Comercio Electrónico se clasifica, desde el punto de vista de los sujetos, en:

1.- B2C Business to Consumer, referido a la venta que realizan las empresas al consumidor final. De igual modo Gutiérrez Tobar (2015) sostiene que "es el medio por el cual las empresas comercializan sus productos a los usuarios finales".(p.89).

2.- B2B Business to Business, consiste en el intercambio entre empresas. Helgueros, (2010) indica que "se considera toda la gama de acciones que puedan ocurrir en dos organizaciones, como por 
ejemplo las compras, la administración de proveedores, administración de pagos, abastecimientos, y tareas como servicio y soporte" (p. 84).

3.-B2G Business to Government, es el comercio de las empresas con el gobierno. La Organización Mundial del Comercio - OMC (2013) refiere :"se entiende por comercio entre las empresas y los gobiernos, o B2G, el comercio electrónico entre las empresas y el sector público" (p.4).

4.- B2E Business to Employee, es el conjunto de productos o servicios que se venden a los empleados a través de las redes internas. Según Nemat (2011) "electronic commerce uses an intrabusiness network which allows companies to provide products and/or services to their employees. Typically, companies use B2E networks to automate employee-related corporate processes" (p.101).

5.- C2C Consumer to consumer, venta entre clientes a través de alguna página web y/o soporte tecnológico.

Estas transacciones se realizan entre los propios consumidores, hay sitios web de subastas, donde un consumidor ofrece un producto, y otros consumidores participan en vista a realizar la compra. Otro tipo de sitios de esta modalidad son los anuncios clasificados, juegos y empleos. (Helgueros, 2010 p. 84).

\section{Comercio Electrónico en América Latina}

El Comercio Electrónico en el mundo y América Latina en particular, ha tenido un incremento considerable, tal cual indica Blacksip (2019): Latinoamérica ha demostrado el gran crecimiento que ha tenido el comercio electrónico en la región. Pasar de casi 105 millones, de compradores a más de 155, durante el periodo 2014-2019, en tan poco tiempo es una evolución sorprendente.(p 5).

\section{Tabla 1}

Evolución del Comercio Digital o E-Commerce en Millones de US\$, 2014-2019

\begin{tabular}{|c|c|}
\hline Número de compradores & Afio \\
\hline 1,32 & 2014 \\
\hline 1,46 & 2015 \\
\hline 1,52 & 2016 \\
\hline 1,66 & 2017 \\
\hline 1,79 & 2018 \\
\hline 1,92 & $\mathbf{2 0 1 9}$ \\
\hline
\end{tabular}

*Cifras en miles de millones.

Fuente: Statista

Nota.- El crecimiento, en el periodo 2014-2019, ha sido del 45.45\%. Tomado de Blacksip 2019 ( P.4) 
Tabla 2

Compradores digitales a nivel mundial en miles de millones, 2014-2019

\begin{tabular}{|c|c|c|c|c|c|c|}
\hline Geography & 2014 & 2015 & 2016 & 2017 & 2018 & 2019 \\
\hline World & $3,201,176.5$ & \begin{tabular}{l|l}
5 & $3,576,386.5$
\end{tabular} & \begin{tabular}{|l|} 
\\
\end{tabular}, 076,$627.4 \mid$ & $4,931,228.7$ & $5,943,415.8$ & $6,833,879.7$ \\
\hline Asia Pacific & $977,337.0$ & $1,241,368.7$ & 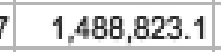 & $1,921,964.9$ & $2,423,892.3$ & $2,829,011.4$ \\
\hline Australasia & $112,846.9$ & $105,003.6$ & $115,574.2$ & $135,550.8$ & $148,311.8$ & $153,489.0$ \\
\hline Eastern Europe & $106,026.5$ & $94,546.8$ & $107,740.6$ & $144,393.1$ & $197,277.8$ & $261,115.8$ \\
\hline Latin America & $134,652.7$ & $134,945.1$ & $149,784.8$ & $193,226.3$ & $220,596.2$ & $260,033.7$ \\
\hline Middle East and Africa & $50,633.3$ & $55,035.9$ & $62,376.3$ & $75,748.4$ & $89,589.1$ & $100,624.5$ \\
\hline North America & $1,249,504.2$ & $1,391,815.9$ & $1,557,773.9$ & $1,790,596.7$ & $2,080,249.6$ & $2,389,302.3$ \\
\hline Western Europe & $570,176.1$ & $553,670.6$ & $594,554.6$ & $669,748.6$ & $783,499.1$ & $840,303.1$ \\
\hline \multicolumn{7}{|l|}{ Sources: } \\
\hline gital Commerce: E & & & & & & \\
\hline
\end{tabular}

Nota.-Durante el periodo 2014-2019, el Comercio Electrónico a nivel mundial ha crecido en $113.48 \%$, en Latinoamérica el crecimiento ha sido de $193.11 \%$. Tomado de Euronomitor

La evolución del E-Commerce implica el desarrollo de la Ciberlegislación, entendida como el conjunto de normas nacionales que garantizan el normal desenvolvimiento del comercio electrónico en un territorio a efectos de fortalecer el desarrollo económico de las economías y regiones en el mundo.

La Ciberlegislación, en palabras de la Conferencia de las Naciones Unidas sobre Comercio y Desarrollo - UNCTAD (2016): "permite promover el comercio nacional y transfronterizo, incluyendo a las entidades gubernamentales de los diferentes niveles de gobierno, a las empresas y/o personas con actividades empresariales, así como a los consumidores y/o ciudadanos". ( p.1). Para efectos del análisis, en el sentido de establecer la legislación que regula la misma, nos enfocaremos en el B2C.

Al respecto, UNCTAD (2016) indica que en "América Latina el B2C ha mostrado un crecimiento de 1,6 mil millones a 70 mil millones de dólares estadounidenses".(p.1). Particularmente el B2C se analiza a través del índice de comercio electrónico, el cual está compuesto por:

a) Porcentaje de personas que usan internet

b) Servidores de internet seguros,

c) Índice de confiabilidad del servicio postal

d) Personas mayores de 15 años con cuenta bancaria.

En cuanto a los resultados obtenidos, destacamos las mismas líneas abajo: 


\section{Tabla 3}

Índice de Comercio Electrónico B2B - UNCTAD 2015

\begin{tabular}{|c|c|c|c|c|c|c|}
\hline Economia & \begin{tabular}{|l|} 
Proporción de la \\
población que \\
recibe correo en \\
el hogar (2012 o \\
posterior, en \%)
\end{tabular} & $\begin{array}{l}\text { Proporción de } \\
\text { personas que } \\
\text { tienen tarjata } \\
\text { de crb́dito (15+, } \\
\text { 2011, en \%) }\end{array}$ & $\begin{array}{l}\text { Proporción de } \\
\text { personas que usan } \\
\text { Intemet (2013 o } \\
\text { posterior, en \%) }\end{array}$ & $\begin{array}{l}\text { Servidores seguros } \\
\text { por cada millón de } \\
\text { personas (normal- } \\
\text { izado en 2013) }\end{array}$ & $\begin{array}{l}\text { Valor del Indlice } \\
\text { de Comercio } \\
\text { Electrónico de la } \\
\text { UNCTAD }\end{array}$ & Categoria \\
\hline Chile & 94 & 22,8 & 61,4 & 73,9 & 63,0 & 39 \\
\hline Uruguay & 93 & 27,1 & 58,0 & 72,1 & 62,5 & 40 \\
\hline Brasil & 81 & 29,2 & 58,0 & 69,9 & 59,5 & 47 \\
\hline Argentina & 93 & 21,9 & 54,1 & 67,6 & 59,1 & 48 \\
\hline Costa Rica & 98 & 12,2 & 47,5 & 72,5 & 57,6 & 52 \\
\hline $\begin{array}{l}\text { República } \\
\text { Dominicana }\end{array}$ & 99 & 12,2 & 45,0 & 61,5 & 54,5 & 57 \\
\hline México & 91 & 13,0 & 43,5 & 63,7 & 52,8 & 60 \\
\hline $\begin{array}{l}\text { República } \\
\text { Bollvariana de } \\
\text { Venezuela }\end{array}$ & 93 & 10,4 & 44,1 & 56,6 & 51,0 & 63 \\
\hline Colombla & 60 & 10,2 & 51,27 & 65,6 & 46,9 & 71 \\
\hline El Salvador & 95 & 5,3 & 25,5 & 60,9 & 46,7 & 72 \\
\hline Ecuador & 68 & 10,2 & 35,1 & 63,0 & 44,1 & 76 \\
\hline Guatemala & 95 & 6,9 & 16,0 & 58,1 & 44,0 & 77 \\
\hline Perú & 56 & 10,0 & 38,2 & 61,9 & 41,5 & 82 \\
\hline Panamá & 25 & 10,7 & 45,2 & 73,5 & 38,6 & 84 \\
\hline Honduras & 75 & 5,3 & 18,1 & 55,1 & 38,4 & 85 \\
\hline Nicaragua & 44 & 2,5 & 13,5 & 54,4 & 28,6 & 98 \\
\hline Bollvia & 19 & 4,1 & 34,2 & 54,9 & 28,1 & 99 \\
\hline Haiti & 40 & 1,8 & 9,8 & 37,7 & 22,3 & 107 \\
\hline
\end{tabular}

Fuente: UNCTAD, 2015.

Nota.- El índice refleja la capacidad de los países para llevar a cabo del comercio electrónico, Destacando, Chile, Uruguay y Brasil. Tomado de UNCTAD 2016 (P.1)

Para el año 2017, los resultados del índice de Comercio Electrónico B2B expresa los siguientes resultados líneas abajo:

La región todavía se encuentra rezagada en este tipo de actividades. Por ejemplo, según el índice de comercio electrónico elaborado por la Conferencia de las Naciones Unidas sobre Comercio y Desarrollo (2017), América Latina y el Caribe muestra un atraso en su nivel de preparación sobre el comercio electrónico en comparación con otras regiones. Excepto,

Chile, los países de la región se encuentran en un nivel bajo o medio de preparación para promover este tipo de actividades. (CEPAL, 2018 p.30)

\section{Tabla 4}

Índice de Comercio Electrónico de UNCTAD, 2017

\begin{tabular}{l|c}
\hline Reglión & $\begin{array}{c}\text { Valor del findlice } \\
(2017)\end{array}$ \\
\hline África & 28 \\
Este, sur y sudeste asiático & 54 \\
América Latina y el Caribe & 47 \\
Asia occidental & 58 \\
Economias en transición & 59 \\
Economias desarrolladas & 87 \\
Mundo & 54 \\
\hline
\end{tabular}

Nota.- Tomado de UNCTAD B2B E-Commerce INDEX 2017 por la Comisión Económica para América Latina y el Caribe - CEPAL, 2018 (P.30) 


\section{Figura 2}

Porcentaje de personas que usan servidores de internet seguros según región del mundo, 2017

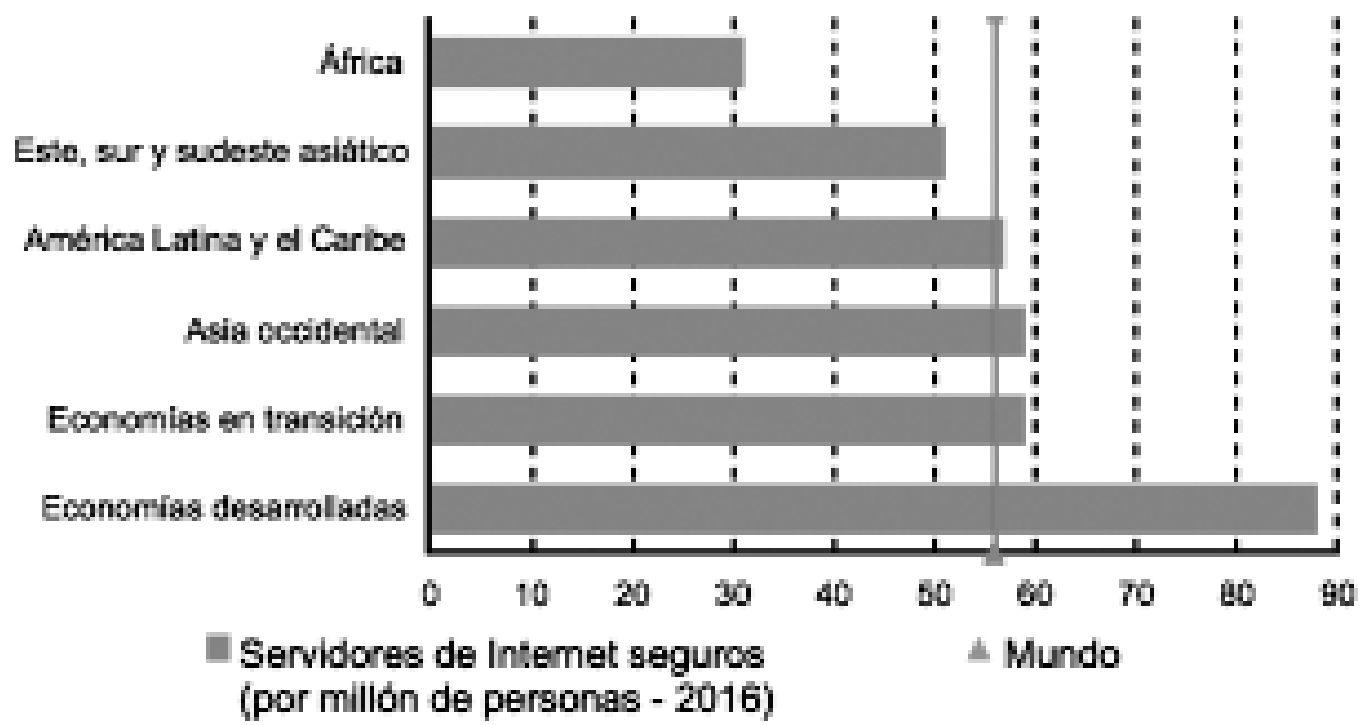

Nota.- América Latina se encuentra ligeramente por encima de la media mundial, pero significativamente por debajo de las economías desarrolladas. Tomado de UNCTAD B2B ECommerce INDEX 2017 por la Comisión Económica para América Latina y el Caribe - CEPAL, 2018 (p.31)

\section{Figura 3}

Porcentaje de personas que usan internet según región del mundo, 2017

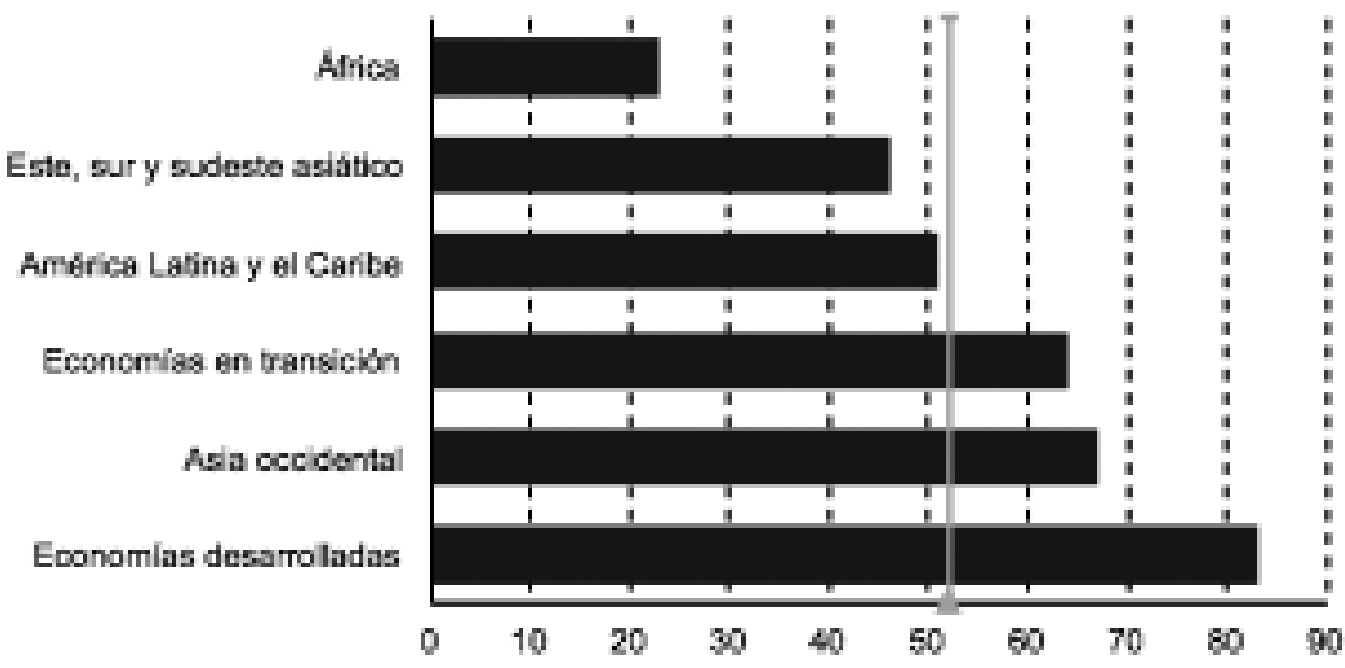

Porcentaje de personas que usan Intemet (2016) M Mundo

Nota.- América Latina se encuentra ligeramente por debajo de la media mundial, pero significativamente por debajo de las economías desarrolladas. Tomado de UNCTAD B2B ECommerce INDEX 2017 por la Comisión Económica para América Latina y el Caribe - CEPAL, 2018 (P.31) 


\section{Figura 4} 2017

Porcentaje del índice de confiabilidad en el servicio postal del UPU, según región del mundo,

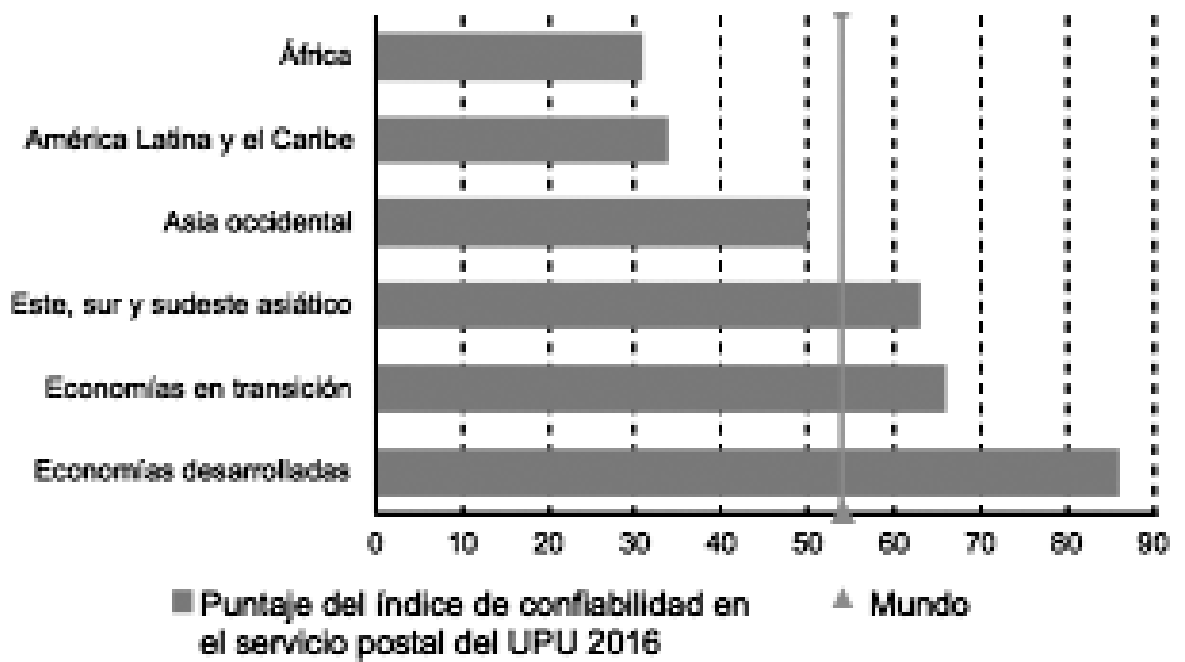

Nota.-América Latina se encuentra rezagado en relación a la media mundial, pero significativamente por debajo de Asia y las Economías Desarrolladas.. Tomado de UNCTAD B2B E-Commerce INDEX 20172017 por la Comisión Económica para América Latina y el Caribe - CEPAL, 2018 (P.31).

\section{Figura 5}

Porcentaje de personas mayores de 15 años con cuenta bancaria, según región del mundo, 2017

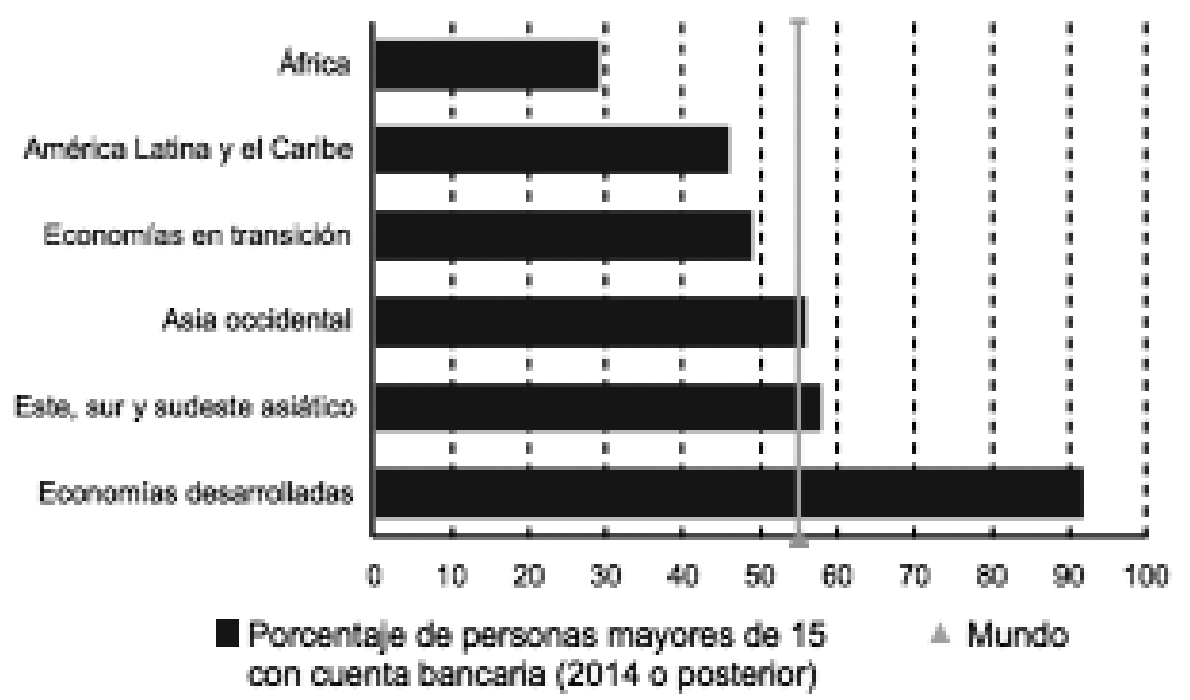

Nota.- América Latina se encuentra por debajo de la media mundial, pero significativamente por debajo de las economías desarrolladas. Tomado de UNCTAD B2B E-Commerce INDEX 20172017 por la Comisión Económica para América Latina y el Caribe - CEPAL, 2018 (P.31) 
Tabla 5

Evolución del Comercio Electrónico en América Latina

\begin{tabular}{|c|c|c|c|c|c|c|c|c|c|c|c|}
\hline & 2009 & 2010 & 2011 & 2012 & 2013 & 2014 & 2015 & 2016 & 2017 & 2018 & 2019 \\
\hline + BRASIL & $\$ 786000$ & $\$ 9,450.00$ & $\$ 9,74000$ & $\$ 12,907.00$ & $\$ 13,460.00$ & $\$ 16,108.00$ & $\$ 18,200.00$ & $\$ 20,835.00$ & $\$ 22,420.00$ & $\$ 25,370.00$ & $\$ 27,730.00$ \\
\hline + MÉXICO & $\$ 1,85000$ & $\$ 2750.00$ & $\$ 4,11000$ & $\$ 6,470.00$ & $\$ 9,200.00$ & $\$ 12200.00$ & $\$ 16,220.00$ & $\$ 17,630.00$ & $\$ 19,800.00$ & $\$ 22,050.00$ & $\$ 24,150.00$ \\
\hline — ARGENTINA & $\$ 1,35800$ & $\$ 1,928.00$ & $\$ 2,66000$ & $\$ 3,460.00$ & $\$ 3148.00$ & $\$ 4,710.00$ & $\$ 7,200.00$ & $\$ 6,661.00$ & $\$ 8,930.00$ & $\$ 7,764.00$ & $\$ 8,200.00$ \\
\hline - COLOMBIA & $\$ 450.00$ & $\$ 66000$ & $\$ 1,35000$ & $\$ 1,900.00$ & $\$ 2,291.00$ & $\$ 2,500.00$ & $\$ 3,045.00$ & $\$ 4320.00$ & $\$ 5,09200$ & $\$ 6,000.00$ & $\$ 7,680.00$ \\
\hline+ CHILE & $\$ 514.00$ & $\$ 73000$ & $\$ 1,06600$ & $\$ 1,275.00$ & $\$ 1,592,00$ & $\$ 2036.00$ & $\$ 2,480.00$ & $\$ 3,074.00$ & $\$ 4,000.00$ & $\$ 5,200.00$ & $\$ 7,00.00$ \\
\hline + PERÚ & $\$ 276.00$ & $\$ 42690$ & $\$ 611.00$ & $\$ 690.00$ & $\$ 1,700.00$ & $\$ 1,900.00$ & $\$ 2,340.00$ & $\$ 2810.00$ & $\$ 3,100.00$ & $\$ 3,500.00$ & $\$ 4,000.00$ \\
\hline - BOLVIA & $\$ 75.00$ & $\$ 100 \infty$ & $\$ 12200$ & $\$ 150.00$ & $\$ 190.00$ & $\$ 230.00$ & $\$ 268.00$ & $\$ 326.00$ & $\$ 42000$ & $\$ 428.00$ & $\$ 670.00$ \\
\hline - ECUADOR & & $\$ 2000$ & $\$ 300.00$ & $\$ 350.00$ & $\$ 400.00$ & $\$ 460.00$ & $\$ 520.00$ & $\$ 600.00$ & $\$ 800.00$ & $\$ 1,000.00$ & $\$ 1,250.00$ \\
\hline
\end{tabular}

Nota.- Tomado de Cámara Peruana de Comercio Electrónico, 2020 (p.7).

\section{CONTENIDO}

\section{1.- La Ciberlegislación en América Latina}

Desde la mirada de la Ciberlegislación y de acuerdo con los avances realizados en la región, podemos señalar los siguientes resultados:

a) Las transacciones electrónicas / Firmas electrónicas: La mayor parte de los países de la región, 19 países, se cuenta ya con legislación en la materia; en 16 de ellos se han incorporado disposiciones conformes con la Ley Modelo sobre Comercio Electrónico y con la Ley Modelo sobre las Firmas Electrónicas de la Comisión de las Naciones Unidas para el Derecho Mercantil Internacional (CNUDMI); en 3 países, la normativa no aplica dichas leyes modelo y en un país no se ha emitido legislación en la materia. El Proyecto de Certificado de Origen Digital de la ALADI, Argentina, Bolivia, Brasil, Cuba, Chile, Colombia, Ecuador, México, Panamá, Paraguay, Perú, Uruguay y Venezuela han logrado importantes avances en el manejo de certificados de origen en formato digital para el comercio transfronterizo. A nivel del Mercado Común del Sur (MERCOSUR), la Resolución N 37/06 - Reconocimiento de la eficacia jurídica del documento electrónico, la firma electrónica y la firma electrónica avanzada en el ámbito del MERCOSUR y la Resolución N 34/06 - Directrices para la celebración de acuerdos de reconocimiento mutuo de firmas electrónicas avanzadas en el ámbito del MERCOSUR , han permitido la adopción de los medios electrónicos en las operaciones aduanales de Argentina, Brasil, Paraguay, Uruguay, Venezuela y Bolivia. De igual forma, con la Decisión 571 Valor en Aduana de las Mercancías Importadas de la Comunidad Andina, Bolivia, Colombia, Ecuador y Perú han impulsado el uso de firmas digitales en las declaraciones electrónicas ante las aduanas de los países miembros. Es importante destacar que Costa Rica, El Salvador, Guatemala, Honduras, Nicaragua, Panamá y República Dominicana han realizado notables progresos a nivel subregional con respecto a la instrumentación del Código Aduanero Único Centroamericano (CAUCA) y el Reglamento del CAUCA, así como con la suscripción del Tratado de Libre Comercio entre la República Dominicana, Centroamérica y Estados Unidos (CAFTA- RD). (UNCTAD, 2016 p. 3).

b) Propiedad Intelectual: En cuanto a la Propiedad Intelectual, la totalidad de los países han suscrito la mayoría de los Tratados administrados por la OMPI, y solamente dos no han suscrito los "Tratados Internet". Entre los avances más representativos en la región, es preciso mencionar el caso de Chile con su Ley № 20.435 que modifica la Ley sobre Propiedad Intelectual (Ley № 17.336), la cual incorpora por primera vez en la región el régimen de "Puerto Seguro", limitado a los temas autorales, en el que instrumenta un procedimiento de "notificación y retiro judicial" y un apartado dedicado al procedimiento judicial sumario que se debe seguir para solicitar el retiro de materiales infractores. De igual forma, Costa Rica incorpora en el Decreto $N^{\circ}$ 36880-COMEX-JP, Reglamento 
sobre la limitación a la responsabilidad de los proveedores de servicios por infracciones a Derechos de Autor y Conexos, un esquema de excluyentes de responsabilidad para los prestadores de servicios. Por su parte Paraguay, en virtud de la Ley sobre Comercio Electrónico (Ley N 4.868/13), incorpora un régimen de exclusión de responsabilidad para los proveedores de los servicios de intermediación, alojamiento de datos, enlaces y de copia temporal. En el ámbito internacional, la suscripción del Tratado de Beijing ${ }^{1}$ sobre Interpretaciones y Ejecuciones Audiovisuales (2012) de la OMPI ha sido uno de los puntos más relevantes, debido a la amplia aceptación del mismo en los Estados de la región, pues lo han firmado Chile, Colombia, Costa Rica, El Salvador, Guatemala, Haití, Honduras, Jamaica, México, Nicaragua y Perú. Sin embargo, su entrada en vigor tendrá lugar tres meses después de que treinta Partes, que reúnan las condiciones mencionadas en el artículo 23, hayan depositado sus instrumentos de ratificación o adhesión. ). (UNCTAD, 2016 p. 4).

c) Nombres de Dominio: En cuanto a los Nombres de Dominio, los registradores nacionales de 18 países han adoptado la normativa referente a la solución de controversias, 12 de los cuales recogen los principios de la Política uniforme de solución de controversias de la Corporación para la Asignación de Nombres y Números de Internet (ICANN, por sus siglas en inglés) y uno no cuenta con instrumentos normativos en la materia. Los procedimientos de solución de controversias que aplica el Centro de Información de Red (NIC) de Haití se apartan de la Política uniforme de solución de controversias en materia de nombres de dominio de la ICANN. La coordinación de las autoridades registradoras de la región por conducto del Registro de Direcciones de Internet para América Latina y el Caribe (LACNIC), bajo la coordinación global de la ICANN, constituye una de las piedras angulares que permiten el desarrollo de Internet en Latinoamérica, Centroamérica y el Caribe. En este sentido, la adopción de la Política uniforme de solución de controversias en materia de nombres de dominio establecida por la ICANN resulta de máxima trascendencia para uniformar los criterios de las autoridades registradoras a nivel regional. En materia de nombres de dominio, tanto el NIC Argentina como el NIC Chile, NIC México, NIC Perú y NIC Venezuela han adoptado, en el marco de sus políticas de solución de controversias, la Política uniforme de solución de controversias en materia de nombres de dominio de la ICANN, y reconocen el procedimiento arbitral del Centro de Arbitraje y Mediación de la OMPI. En el caso de Perú, también se reconoce como instancia arbitral al Cibertribunal Peruano. Por su parte, el NIC Paraguay dirime sus controversias sobre nombres de dominio mediante mecanismos extrajudiciales regidos por la Ley $\mathrm{N}^{\circ} 1.879 / 02$ de Arbitraje y Mediación. Adicionalmente, el CAFTA-RD obliga a los países miembros a establecer mecanismos para combatir la piratería cibernética mediante la instrumentación de procedimientos basados en los principios de la Política uniforme de solución de controversias. Sobre el particular, los procedimientos de solución de controversias utilizados por el NIC de Costa Rica, El Salvador, Honduras y República Dominicana se apartan de la Política uniforme de solución de controversias en materia de nombres de dominio de la ICANN, cuestión que puede inhibir el desarrollo de negocios transfronterizos en la región. (UNCTAD, 2016 p. 5).

d) Protección al Consumidor: En cuanto a la Protección al Consumidor, en 18 países se han promulgado leyes, 11 de los cuales han aplicado la Resolución 39/248 sobre las Directrices para la Protección al Consumidor, aprobada por la Asamblea General de las Naciones Unidas, y en 2 países no se han promulgado leyes en la materia ni se cuenta con proyectos de Ley. A nivel del MERCOSUR, la Resolución N²1/04 - Derecho a la Información del Consumidor en las Transacciones Comerciales efectuadas a través de Internet, la Resolución del MERCOSUR N 45/06 - Defensa del Consumidor - Publicidad Engañosa y el Decreto № 10/96 - Protocolo de Santa María MERCOSUR 10/96 sobre Jurisdicción Internacional en materia de relaciones de consumo han facilitado la armonización normativa sobre esos temas para Argentina, Brasil, Paraguay, Uruguay, Venezuela y Bolivia. Adicionalmente, en el ámbito de la autorregulación, diversas cámaras y asociaciones nacionales han desarrollado Códigos de Conducta y esquemas de Sellos de Confianza relacionados

El Tratado fue adoptado en Beijing el 24 de junio de 2012 , y entró en vigor respecto de sus 30 partes contratantes el 28 de abril de 2020. 
con el comercio electrónico. La participación de los países centroamericanos en el CAFTA-RD y el Tratado de Promoción Comercial entre Panamá y Estados Unidos ha permitido incentivar la adopción de este tipo de mecanismos. Algunos países, como México y Chile, ya habían incorporado en su normativa interna las Directrices para la Protección de los Consumidores en el Contexto del Comercio Electrónico (1999) y las Directrices de la OCDE para la Protección de los Consumidores de Prácticas Comerciales Transfronterizas, Fraudulentas y Engañosas. De igual forma, habían participado en el proyecto "Pathfinder de privacidad" del Foro de Cooperación Económica AsiaPacífico (APEC). (UNCTAD, 2016 p. 4).

e) Protección de Datos: La mayoría de los países han adoptado leyes en materia de Protección de Datos Personales: en 19 países ya se han promulgado leyes, siendo diez los países que observan las Directrices formuladas por la Red Iberoamericana de Protección de Datos; en un país no se han promulgado leyes en la materia ni cuenta con proyectos de ley. (UNCTAD, 2016 p. 4).

f) Delitos Informáticos: Por lo que respecta a los ciberdelitos, dos países han suscrito el Convenio del Consejo de Europa sobre la Ciberdelincuencia y han modificado sus leyes sustantivas y procesales de conformidad con ese instrumento; en 17 países hay leyes que tipifican algunos delitos informáticos y, en uno, no hay normativa alguna. Respecto de la Seguridad de la Información son 13 los países que tienen un Centro de Respuesta a Incidentes Cibernéticos (CSIRT, CERT o CIRT) y que han adoptado las recomendaciones del Comité Interamericano contra el Terrorismo (CICTE) de la Organización de los Estados Americanos (OEA). A nivel subregional, desde 2012 la Unión de Naciones Suramericanas (UNASUR) ha venido trabajando en Planes de Acción anuales del Consejo de Defensa Suramericano en virtud de los cuales ha conformado un Grupo de Trabajo para evaluar la factibilidad de establecer políticas y mecanismos regionales a fin de hacer frente a las amenazas cibernéticas o informáticas en el ámbito de la defensa. En 2013, el Grupo de Trabajo realizó un Seminario Regional de Ciberdefensa con el objetivo de generar capacidades para enfrentar los desafíos de las amenazas cibernéticas e informáticas del ámbito de la defensa. Participaron en este Seminario el Consejo Suramericano de Infraestructura y Planeamiento (COSIPLAN) y el Grupo de trabajo sobre Telecomunicaciones del MERCOSUR. En 2014, la Conferencia de Ministros de Justicia de los Países Iberoamericanos (COMJIB) suscribió el Convenio Iberoamericano de Cooperación sobre Investigación, Aseguramiento y Obtención de Prueba en materia de Ciberdelincuencia, que tiene por objeto reforzar la cooperación mutua de las Partes para la adopción de medidas de aseguramiento y obtención de pruebas para la lucha contra la ciberdelincuencia, así como la Recomendación relativa a la Tipificación y Sanción de la Ciberdelincuencia, los instrumentos han sido suscritos por México, Guatemala, Nicaragua, Portugal, Perú y Uruguay y firmado por Argentina Los instrumentos precitados representan el mayor avance regional en cuanto a la atención señalada a esta problemática, derivado de las carencias que las leyes penales iberoamericanas tienen respecto de los tipos penales referidos al ciberdelito, y al hecho de que estas lagunas permiten tanto a la delincuencia individual como a la organizada lesionar o poner en grave peligro los bienes jurídicos esenciales con el propósito de establecer criterios mínimos y comunes en la prevención y luchas contra el ciberdelito, y sin menoscabar los avances alcanzados en los respectivos ordenamientos jurídicos así como las obligaciones internacionales asumidas por cada Estado, la COMJIB recomienda armonizar, en el marco de las políticas criminales de cada país, leyes penales sustantivas que tipifiquen las conductas que se describen a continuación, en aras de lograr una mayor eficacia en la prevención, persecución y sanción de dichos ilícitos para facilitar la cooperación judicial entre los distintos países y tratar de impedir la existencia de espacios de impunidad. El Convenio es compatible con otros instrumentos internacionales, como el Convenio del Consejo de Europa sobre la Ciberdelincuencia. Merece especial mención la "Declaración Especial Sobre procesos de gobernanza en Internet" adoptada durante la III Cumbre de la Comunidad de Estados Latinoamericanos y Caribeños (CELAC) celebrada en Belén (Costa Rica), en enero de 2015, en la que Jefas y Jefes de Estado y de Gobierno de los treinta y tres Estados de la región manifestaron lo siguiente: i) la aspiración de convertir a América Latina y el Caribe en una región de 
redes de conocimiento ii) su condena decidida contra las acciones de espionaje y vigilancia masiva y global indiscriminada entre los países por parte de actores públicos y privados, exigiendo absoluto acatamiento a las normas del derecho internacional, en relación con el respeto a la soberanía de los estados y a los derechos humanos, en especial el derecho a la privacidad y iii) su compromiso para promover acciones y estrategias para fortalecer la ciberseguridad y prevenir los delitos informáticos, articulando mecanismos para la erradicación de la guerra cibernética y la promoción de Internet como un espacio de paz. (UNCTAD, 2016 p. 6).

\section{Figura 6}

Estado de la Ciberlegislación en América Latina, 2015

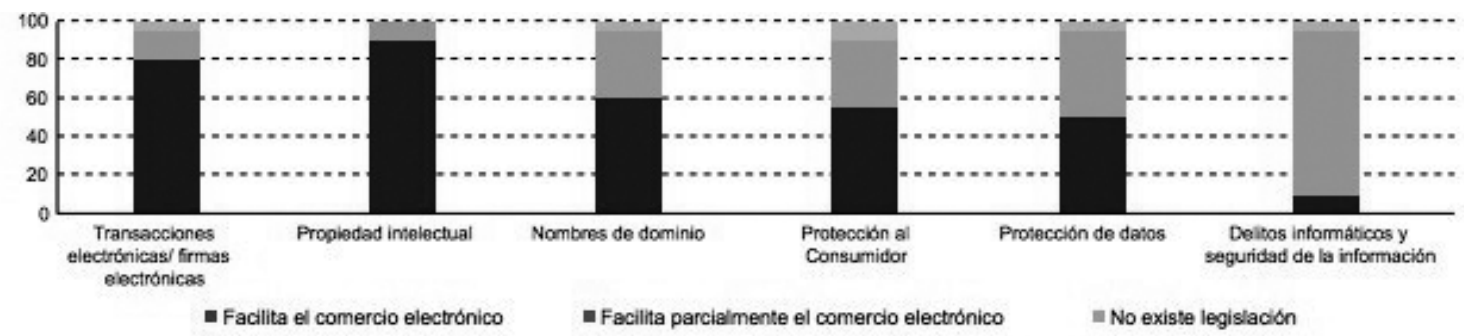

Fuente: Comisión Económica para América Latina y el Carbe (CEPAL), sobre la base de Conterencia de las Naciones Unidas sobre Comercio y Desarrollo (UNCTAD) (2016). Examen de la armonización de la ciberlegislación en América Latina, 2016.

Nota.- Los países analizados incluyen, Argentina, Bolivia, Brasil, Chile, Colombia, Costa Rica, Cuba, Ecuador, EI Salvador, Guatemala, Haití, Honduras, México, Nicaragua, Panamá, Paraguay, Perú, República Dominicana, Uruguay y Venezuela. Tomado de UNCTAD B2B E-Commerce INDEX 20172017 por la Comisión Económica para América Latina y el Caribe - CEPAL, 2018 (P.31)

\section{Tabla 6}

Estado de la Ciberlegislación en los países de América Latina, 2015

\begin{tabular}{|c|c|c|c|c|c|c|}
\hline Pais & $\begin{array}{l}\text { Transaccio- } \\
\text { neselectróni- } \\
\text { cas/ firmas } \\
\text { electrónicas }\end{array}$ & $\begin{array}{l}\text { Protección al } \\
\text { Consumidor }\end{array}$ & $\begin{array}{l}\text { Protección de } \\
\text { Datos }\end{array}$ & $\begin{array}{l}\text { Propiedad Intelec- } \\
\text { tual }\end{array}$ & $\begin{array}{l}\text { Nombres de } \\
\text { dominio }\end{array}$ & $\begin{array}{l}\text { Delitos } \\
\text { Informáticos y } \\
\text { Seguridad de la } \\
\text { Información }\end{array}$ \\
\hline \multicolumn{7}{|l|}{ Argentina } \\
\hline \multicolumn{7}{|l|}{ Bolivia } \\
\hline \multicolumn{7}{|l|}{ Brasil } \\
\hline \multicolumn{7}{|l|}{ Chile } \\
\hline \multicolumn{7}{|l|}{ Colombia } \\
\hline \multicolumn{7}{|l|}{ Costa Rica } \\
\hline \multicolumn{7}{|l|}{ Cuba } \\
\hline \multicolumn{7}{|l|}{ Ecuador } \\
\hline \multicolumn{7}{|l|}{ El Salvador } \\
\hline \multicolumn{7}{|l|}{ Guatemala } \\
\hline \multicolumn{7}{|l|}{ Haiti } \\
\hline \multicolumn{7}{|l|}{ Honduras } \\
\hline \multicolumn{7}{|l|}{ México } \\
\hline \multicolumn{7}{|l|}{ Nicaragua } \\
\hline \multicolumn{7}{|l|}{ Panamá } \\
\hline \multicolumn{7}{|l|}{ Paraguay } \\
\hline \multicolumn{7}{|l|}{ Perú } \\
\hline \multicolumn{7}{|c|}{$\begin{array}{l}\text { República } \\
\text { Dominicana }\end{array}$} \\
\hline \multicolumn{7}{|l|}{ Uruguay } \\
\hline Venezuela & & & & & & \\
\hline
\end{tabular}




\begin{tabular}{|c|c|c|}
\hline \multicolumn{3}{|c|}{ Valores Normativos: } \\
\hline Valor & Enunciado & Descripción \\
\hline & Facilita el comercio electrónico & 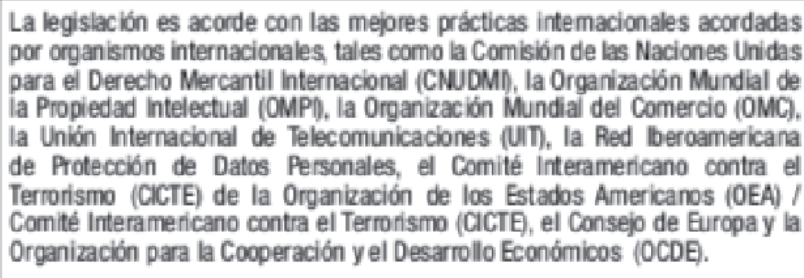 \\
\hline & $\begin{array}{l}\text { Facilita parcialmente el comercio } \\
\text { electrónico. }\end{array}$ & $\begin{array}{l}\text { Existe legislación en la materia, sin embargo, no es acorde con las mejores } \\
\text { prácticas internacionales. Hace falta homologación normativa. }\end{array}$ \\
\hline & No existe legislación. & \\
\hline
\end{tabular}

Nota.- Tomado de UNCTAD, 2016 (p.2)

De acuerdo a las estadísticas, al 2019, CEPAL (2019) indica que la región muestra grados disímiles de avance en las distintas dimensiones normativas relevantes, siendo particularmente marcado su rezago en la crucial área de la protección de la información personal. (p.14). Al respecto mostramos el gráfico líneas abajo:

\section{Tabla 7}

Estado de los principales aspectos de la Ciberlegislación en los países de América Latina, 2019

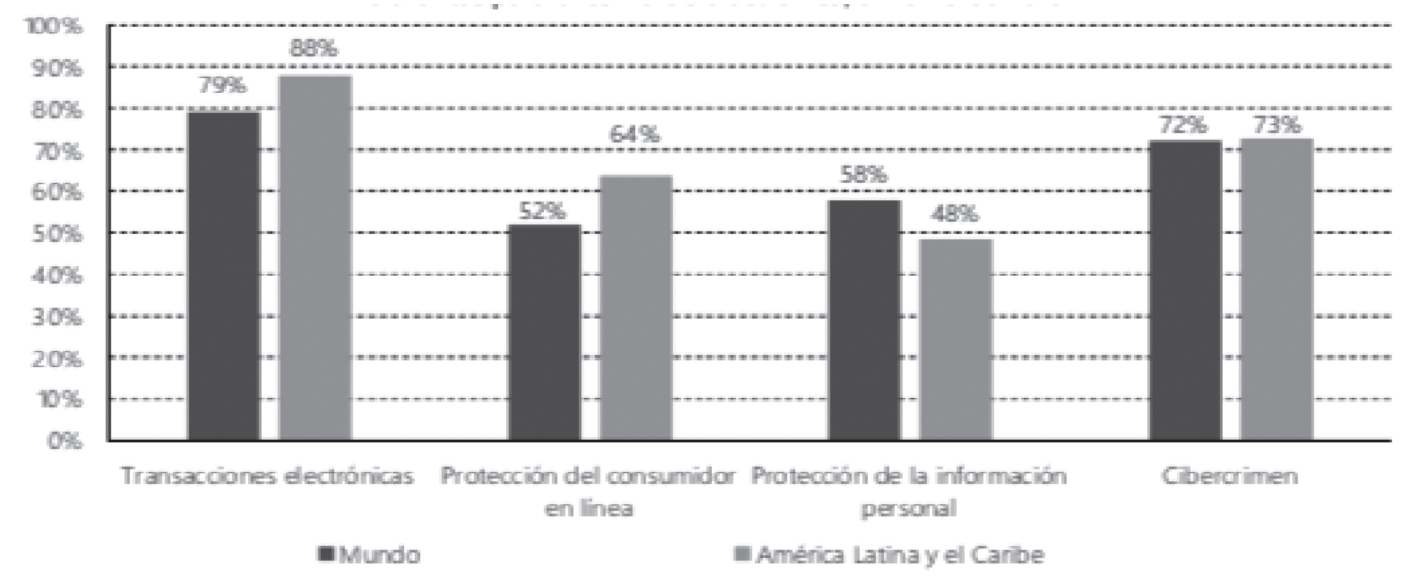

Fuente: Autor, sobre la base de UNCTAD, Global Cyberlaw Tracker, [en linea] hittps//functadiorg/en/Pages/DTL/STI_and_JCTs/KCT4DLegislation/eCom-Global-Legislation aspx (consultado el 15 de abrilde 2019).

Nota.- Tomado de CEPAL 2019 (p.14)

\section{La Ciberlegislación en el Perú}

En el Plan de Desarrollo de la Sociedad de la Información en el Perú - La Agenda Digital 2.0, mediante Decreto Supremo No 066-2011-PCM, de julio de $2001^{2}$, que incluyó como estrategia el Desarrollo del Comercio Electrónico. Adicionalmente, la Política Nacional de Gobierno Electrónico 2013-2017, aprobada mediante Decreto Supremo Nº81-2013, la Ley de Promoción de la Banda Ancha y Construcción de la Red Dorsal Nacional de Fibra Óptica (Ley N²9904), del 20 de

2 Mediante D.S. 065-2015-PCM se Crea la Comisión Multisectorial Permanente encargada del seguimiento y evaluación del "Plan de Desarrollo de la Sociedad de la Información en el Perú - La Agenda Digital Peruana 2.0" CODESI 
julio de 2012, y su Reglamento, del 4 de noviembre de 2013, así como el Decreto Legislativo $N^{\circ} 604$ que aprueba la Ley de Organización y Funciones del Instituto Nacional de Estadística e Informática, del 30 de abril de 1990. Entre las principales leyes que rigen el comercio electrónico se encuentra la Ley N² 27291, del 24 de junio de 2000, que modifica al Código Civil, Ley de Firmas y Certificados Digitales, o Ley $N^{\circ} 27269$, del 26 de mayo de 2000 , modificada por la Ley $\mathrm{N}^{\circ} 27310$ Ley de Firmas y Certificados Digitales, así como el Reglamento de la Ley de Firmas y Certificados Digitales (RLFCD) por Decreto Supremo N 052-2008/PCM, aprobado el 18 de julio de 2008. Por su parte, la Presidencia del Consejo de Ministros, a través de la Oficina Nacional de Gobierno Electrónico e Informática (ONGEI), promueve en las instituciones públicas la adopción de las TIC para la prestación de sus servicios en línea y promueve el desarrollo de seminarios en materia de "Gobierno Electrónico y Sociedad de la Información" para capacitar a los funcionarios públicos en temas relacionados con el gobierno electrónico y su marco jurídico, el gobierno abierto, las estadísticas TIC en el Estado, la Sociedad de la Información e Inclusión y Ciudadanía Digital para la Modernización del Estado y la mejora de la gestión pública. . (UNCTAD, 2016 p.57).

En el mismo sentido, el Decreto Supremo $N^{\circ}$ 016-2017-PCM que Aprueba la Estrategia Nacional de Datos Abiertos Gubernamentales 2017 - 2021 y del Modelo de Datos Abiertos Gubernamentales del Perú. • Decreto Supremo N¹21-2017-PCM, que amplía la información para la implementación progresiva de la interoperabilidad en beneficio del ciudadano, en el marco del Decreto Legislativo $N^{\circ}$ 1246. - Decreto Supremo $N^{\circ} 118-2018-\mathrm{PCM}$, que declara de interés nacional el desarrollo del Gobierno Digital, la innovación y la economía digital con enfoque territorial. - Decreto Supremo $N^{\circ}$ 033-2018-PCM, que crea la Plataforma Digital Única del Estado Peruano y establecen disposiciones adicionales para el desarrollo del Gobierno Digital. • Decreto Supremo N 050-2018-PCM, que aprueba la definición de Seguridad Digital en el Ámbito Nacional. • Resolución Ministerial N¹19-2018- PCM, que dispone la creación de un Comité de Gobierno Digital en cada entidad de la Administración Pública. • Resolución Ministerial N 087 2019-PCM, aprueban disposiciones sobre la conformación y funciones del Comité de Gobierno Digital • Resolución de Secretaría de Gobierno Digital Nº05-2018-PCM/SEGDI, que aprueba los lineamientos para la formulación del Plan de Gobierno Digital. • Resolución de Secretaría de Gobierno Digital Nº04-2018-PCM/SEGDI, que aprueba los lineamientos del Líder de Gobierno Digital. Finalmente, en febrero del 2019, el Perú se ha adherido al al Convenio del Consejo de Europa sobre la Ciberdelincuencia.

a) Transacciones electrónicas / Firmas electrónicas: En materia de transacciones electrónicas, destaca la Ley $\mathrm{N}^{\circ} 27291$, que modifica al Código Civil, y señala que cuando la Ley establezca que la manifestación de voluntad deba hacerse a través de alguna formalidad expresa o requiera de firma, ésta podrá ser generada o comunicada por medios electrónicos, ópticos o cualquier otro análogo, y dispone que, en materia de contratación entre ausentes, la oferta, su revocación, su aceptación y cualquier otra declaración contractual se consideran conocidas en el momento en que llegan a la dirección del destinatario. Si se realizan a través de medios electrónicos, ópticos u otro análogo, se presumirá la recepción de la declaración contractual cuando el remitente reciba el acuse de recibo. Por su parte, la Ley de Firmas y Certificados Digitales o Ley № 27269 de 2000, reformada mediante la Ley $N^{\circ} 27310$, que modifica el artículo 11 de la Ley № 27269 de 2000, establece los lineamientos generales que rigen la firma digital y la certificación digital, así como las atribuciones de la autoridad competente y la actuación de las entidades de certificación y de registro o verificación. La Ley establece que la firma digital tiene la misma validez y eficacia jurídica que la firma manuscrita u otras análogas que conlleven una manifestación de voluntad. De igual forma, reconoce los certificados de firmas digitales emitidos por entidades extranjeras, siempre y cuando tales certificados sean reconocidos por la autoridad administrativa competente. En este sentido, el Reglamento de la Ley de Firmas y Certificados Digitales (RLFCD) (Decreto Supremo $N^{\circ}$ 052-2008/PCM), promulgado por la Presidencia del Consejo de Ministros, y que 
refleja algunos temas previstos en la Ley Modelo de la CNUDMI sobre las Firmas Electrónicas, fue emitido para el ámbito del sector público como en el privado, la utilización de firmas electrónicas y el régimen de la Infraestructura Oficial de Firma Electrónica (IOFE). El Reglamento designa al Instituto Nacional de Defensa de la Competencia y de la Protección de la Propiedad Intelectual (INDECOPI) como Autoridad Administrativa Competente y al Registro Nacional de Identificación y Estado Civil (RENIEC) como Entidad de Certificación Nacional para el Estado Peruano (ECERNEP), Entidad de Certificación para el Estado Peruano (ECEP) y Entidad de Registro o Verificación para el Estado Peruano (EREP). El Reglamento otorga a la firma digital generada dentro de la Infraestructura Oficial de Firma Electrónica (IOFE) la misma validez y eficacia jurídica que a la firma manuscrita. De igual forma, señala que los documentos electrónicos firmados digitalmente en el marco de la IOFE deberán ser admitidos como prueba en los procesos judiciales y/o procedimientos administrativos. La IOFE es un sistema confiable, acreditado, regulado y supervisado por la Autoridad Administrativa Competente, provisto de instrumentos legales y técnicos que permiten generar firmas digitales y proporcionar diversos niveles de seguridad respecto de la integridad de los documentos electrónicos y de la identidad de su autor. Mediante Decreto Supremo № 070-2011-PCM, del 27 de julio de 2011, que modifica el Reglamento de la Ley $N^{\circ}$ 27269, Ley de Firmas y Certificados Digitales, y establece normas aplicables al procedimiento registral en virtud del Decreto Legislativo $\mathrm{N}^{\circ} 681$ y ampliatorias, se modifican los requerimientos en cuanto al contenido y la vigencia de los certificados digitales para las personas naturales y las personas jurídicas y se reconoce la atribución del INDECOPI para cumplir con su función de Autoridad Administrativa Competente de la IOFE. De igual forma, en virtud del Decreto Supremo No 105-2012-PCM, del 21 de octubre de 2012, se establecen disposiciones para facilitar la puesta en marcha de la firma digital y modifican el Decreto Supremo № 052-2008-PCM, Reglamento de la Ley de Firmas y Certificados Digitales. Mediante el citado instrumento se permite a las personas naturales y jurídicas utilizar un certificado digital emitido por proveedores que cuenten con la certificación internacional Web Trust, hasta en tanto cuente con el certificado digital del INDECOPI. Por su parte, la Comisión Nacional Supervisora de Empresas y Valores (CONASEV) emitió su Resolución № 008 - 2003, del 7 de febrero de 2003, en virtud de la cual aprueba el Reglamento del Sistema MVNet, que regula el sistema de transmisión e intercambio de documentos e información a través de la Red del Mercado de Valores Peruano (MVNet), que opera con tecnología de PKI. Las personas naturales y jurídicas que se encuentren dentro del ámbito de supervisión y control de la Comisión deberán utilizar obligatoriamente esta Red, para remitirle toda la información y documentación que se encuentran obligadas a proporcionar. En el ámbito de las transacciones gubernamentales en línea, la Ley del Procedimiento Administrativo General (Ley $N^{\circ} 27444$ ), del 10 de abril de $2001^{3}$, regula, entre otros temas, las notificaciones vía medios electrónicos u otros medios que permitan comprobar fehacientemente su acuse de recibo y quién lo recibe, siempre que haya sido solicitado expresamente por el administrado. De igual forma autoriza el uso de medios electrónicos para las comunicaciones al interior de laAdministración Pública. Asimismo, autoriza a los administrados a solicitar el envío de información o documentación relacionada con un proceso administrativo a través de medios de transmisión a distancia. En la actualidad, el Sistema Electrónico de Contrataciones del Estado (www.seace.gob.pe) permite el intercambio de información y difusión sobre adquisiciones y contrataciones del Estado, así como la realización de transacciones electrónicas. Por otra parte, con base en el Reglamento de la Ley de Firmas y Certificados Digitales (RLFCD) se faculta a la Oficina Nacional de Gobierno Electrónico e Informática (ONGEI) para supervisar los planes que las entidades de la Administración Pública elaboren con miras a la implementación de los procedimientos y trámites administrativos por medios electrónicos seguros. En el ámbito fiscal, el Decreto Supremo N 135-99, Código Tributario, del 19 de agosto de 1999, modificado por Decreto Legislativo № 953, del 5 de febrero de 20044, faculta a la Administración Tributaria para autorizar la presentación de declaraciones a través de

3 Actualizada los cambios normativos a través del Texto Único Ordenado de la Ley Nº 27444 ( D.S. 004-2019-JUS), Ley del Procedimiento Administrativo General.

4 D.S. 133-2013- EF, que aprueba el TUO del Código Tributario 
medios magnéticos, fax, transferencia electrónica o cualquier medio que cumpla las condiciones que establezca la Superintendencia Nacional de Aduanas y de Administración Tributaria (SUNAT). Con base en ello, la SUNAT ha desarrollado los Programas de Declaración Telemática (PDT). Asimismo, en virtud del Decreto No 809, Ley General de Aduanas, del 19 de abril de $1996^{5}$, y su Reglamento, aprobado mediante Decreto Supremo N 011-2005-EF, del 26 de enero de 2005, que rigen las actividades aduaneras de las personas, mercancías y medios de transporte que crucen las fronteras aduaneras, se faculta a la Aduana para expedir normas y establecer procedimientos que regulen la emisión, transferencia, uso y control de la información, a través de medios documentales, magnéticos o electrónicos, a efectos de promover el desarrollo y facilitación de las actividades aduaneras. En este sentido, el Ministerio de Comercio Exterior y Turismo (MINCETUR) tiene a su cargo el desarrollo del sistema de Ventanilla Única de Comercio Exterior (VUCE), creada mediante Decreto Supremo N N 165-2006-MEF, del 3 de noviembre de $2006^{6}$, otorgándose rango de Ley a su creación a través de la Primera Disposición Complementaria del Decreto Legislativo $N^{\circ} 1036$, del 24 de junio de 2008. La VUCE permite a las partes involucradas en el comercio y transporte internacional gestionar, a través de medios electrónicos, los trámites requeridos por las diversas entidades competentes, de acuerdo con la normatividad vigente, o solicitados por dichas partes para el tránsito, ingreso o salida del territorio nacional de las mercancías, y la instrumentación de las disposiciones en materia de comercio electrónico consignadas en los Tratados de Libre Comercio con Estados Unidos de Norteamérica y Canadá, así como los compromisos del Grupo de Comercio Electrónico del APEC en materia de comercio sin papel. (UNCTAD, 2016 p.57- 59).

b) Protección al consumidor: La Ley N²9571, Código de Protección y Defensa del Consumidor, del 1 de septiembre de 2010. Entre las medidas más relevantes se encuentra la facultad que se otorga al consumidor para desvincularse del contrato utilizando los mismos mecanismos de forma, lugar y medios utilizados para la celebración de los contratos, incluyendo los medios electrónicos. También establece que los proveedores deben acreditar que entregaron oportunamente a los usuarios en línea copia de los contratos, incluyendo las condiciones generales de contratación, y deben proporcionar información sobre su identificación, domicilio, correo electrónico y otros datos de contacto. Asimismo, prohíbe realizar proposiciones no solicitadas por correo electrónico, de manera persistente o ignorando la petición del consumidor para que cese este tipo de actividades. También prohíbe el envío de mensajes electrónicos masivos para promover productos y servicios, así como prestar el servicio de telemercadeo a las direcciones electrónicas que hayan sido incorporadas en el registro implementado por el Indecopi para registrar a los consumidores que no deseen recibir este tipo de promociones. También dispone que los establecimientos comerciales deben contar con un Libro de Reclamaciones, en forma física o virtual. Mediante Decreto Supremo $\mathrm{N}^{\circ}$ 011-2011-PCM, aprobado el 28 de febrero de 2011, se aprobó el Reglamento del Libro de Reclamaciones del Código de Protección y Defensa del Consumidor, siendo este modificado mediante Decreto Supremo No 006-2014- PCM, del 23 de enero de 2014, que señala respecto al Libro de Reclamaciones, que cada establecimiento comercial abierto al público deberá contar con un Libro de Reclamaciones, donde los proveedores que utilicen medios virtuales para establecer sus relaciones de consumo deberán implementar un Libro de Reclamaciones Virtual en cada uno de sus establecimientos y deberán brindar el apoyo necesario para que el consumidor ingrese su queja o reclamo en el Libro de Reclamaciones. La Ley de Represión de la Competencia Desleal, adoptada mediante Decreto Legislativo $N^{\circ} 1044$, del 25 de junio de 2008, regula la publicidad en línea y faculta al INDECOPI para sancionar a quienes utilizando medios electrónicos, incluyendo el Internet, difundan información que impida el adecuado funcionamiento del proceso competitivo, mediante actos que induzcan a los consumidores al engaño o la confusión. (UNCTAD, 2016 p. 59)

\footnotetext{
Modificado por el D. L 1053 y su reglamento el D.S. 010-2009-EF

6 Ley 30809 que modifica la ley 28977, Ley de facilitación del Comercio Exterior y Ley 30264, Ley que establece medidas para promover el crecimiento económico.
} 
c) Protección de datos personales: La Ley de Protección de Datos Personales (Ley $N^{\circ}$ 29733), del 3 de julio de 2011, está en consonancia con las Directrices para la Armonización de la Protección de Datos en la Comunidad Iberoamericana emitidas por la Red Iberoamericana de Protección de Datos Personales. La Ley protege los datos personales, automatizados o no, de toda persona natural o jurídica, y el manejo de esta información en bancos de datos públicos o privados, a efectos de garantizar el derecho a la privacidad de las personas. La Autoridad Nacional de Protección de Datos Personales, adscrita a la Dirección Nacional de Justicia del Ministerio de Justicia y Derechos Humanos, es la entidad a cargo de supervisar la aplicación de la Ley. La Ley distingue los datos personales de los datos sensibles. También establece la obligación de registrar los bancos de datos públicos o privados en el Registro Nacional de Protección de Datos Personales y prohíbe la transferencia de datos personales a países que no proporcionen niveles de seguridad y protección adecuados. Las personas naturales, las personas jurídicas de derecho privado y las entidades públicas que hacen uso, almacenan o transfiere en información privada de los titulares de los datos se encuentran obligadas a: i) que el uso de la información sea adecuado, proporcional y necesario en relación con el ámbito y las finalidades para el que se colecta; ii) obtener consentimiento del titular para la entrega de los datos; iii) usar los datos para los fines que motivaron su obtención, y iv) adoptar las medidas técnicas, organizativas y legales para garantizar la seguridad y confidencialidad de los datos personales. La violación a la Ley se castiga con sanciones administrativas y penales. La Ley otorga al titular de los datos el derecho a la información, el derecho de acceso, derecho de actualización, inclusión, rectificación y supresión, así como el derecho de oposición, derecho a impedir el suministro, derecho al tratamiento objetivo y el derecho a la indemnización. La Ley clasifica las infracciones en leves, graves y muy graves, estableciendo sanciones administrativas, con independencia de la responsabilidad civil y penal que pueda derivar. Mediante el Reglamento de la Ley de Protección de Datos Personales (Ley N ${ }^{\circ}$ 29733), emitido mediante Decreto Supremo No 003-2013-JUS, del 22 de marzo de 2013, y con la Directiva de Seguridad de la Información Administrada por los Bancos de Datos Personales, emitida por la Autoridad Nacional de Datos Personales, de octubre de 2013, se completa el régimen normativo para la protección de los datos personales. (UNCTAD, 2016 p.59)

d) Propiedad industrial e intelectual: En materia de propiedad intelectual, en virtud del Decreto Legislativo № 822, Ley sobre el Derecho de Autor, del 23 de abril de 1996, la normativa del Perú incorpora diversas medidas contenidas en el Convenio de Berna, el ADPIC, la Decisión 351 de la Comisión del Acuerdo de Cartagena, que aprueba el Régimen Común sobre Derechos de Autor y Derechos Conexos. Asimismo, regula las sociedades de gestión colectiva y protege a los autores de las bases de datos, en términos similares a los establecidos en el ADPIC. En virtud del Decreto Legislativo No 1076, la Ley Modificatoria del Decreto Legislativo № 822, del 27 de junio de 2008, incorpora la utilización de medidas tecnológicas para la protección de obras y los sistemas de información sobre la gestión de derechos. Es importante señalar que, en el ámbito internacional, Perú ha suscrito: • los Tratados de Internet de la OMPI, tanto el WCT como el WPPT, y - el Tratado de Beijing sobre Interpretaciones y Ejecuciones Audiovisuales. En el ámbito de la propiedad industrial, el Decreto Legislativo $N^{\circ} 823$, Ley de Propiedad Industrial, del 23 de abril de 1996, incorporó distintas medidas de la Decisión 344 de la Comisión del Acuerdo de Cartagena, el Régimen Común sobre Propiedad Industrial para los Países Andinos, el Convenio de París para la Protección de la Propiedad Industrial y el ADPIC. La Ley regula, entre otras cuestiones, las patentes de invención, los certificados de protección, los modelos de utilidad, los diseños industriales, los secretos industriales, las marcas, los nombres comerciales, los lemas comerciales y las denominaciones de origen. Entre las medidas importantes para combatir la piratería, Perú adoptó el Decreto Legislativo $N^{\circ} 1092$, del 27 de junio de 2008, que aprueba medidas en frontera para la protección de los derechos de autor y derechos conexos y los derechos de marcas. (UNCTAD, 2016 p.60) 
e) Nombres de dominio: En materia de nombres de dominio, la Red Científica Peruana se encarga de administrar los dominios peruanos (.pe) y ha adoptado dentro de sus políticas de resolución de disputas los principios de la Política uniforme de solución de controversias en materia de nombres de dominio de la ICANN, y reconoce como instancias para resolver las controversias al Centro de Arbitraje y Mediación de la OMPI y al Cibertribunal Peruano. (UNCTAD, 2016 p.60)

f) Delitos Informáticos y Seguridad de la Información: En el ámbito penal, con la Ley $\mathrm{N}^{\circ}$ 30171, del 10 de marzo de 2014, que modifica la Ley de Delitos Informáticos (Ley $\mathrm{N}^{\circ}$ 30096), se amplió el contenido de diversos tipos penales, incluyendo los delitos de: i) acceso ilícito a sistemas informáticos; ii) atentado a la integridad de datos informáticos; iii) atentado a la integridad de sistemas informáticos; iv) pornografía infantil por medios tecnológicos; v) interceptación de datos informáticos; vi) fraude informático; vii) abuso de mecanismos y dispositivos informáticos, y viii) tráfico ilegal. De igual forma, se establecieron medidas de coordinación interinstitucional entre la Policía Nacional, el Ministerio Público y otros organismos especializados. También se establecieron disposiciones para exentar de responsabilidad penal a los prestadores de servicios de telecomunicaciones. Se incluyeron medidas para llevar a cabo la intervención, grabación o registro de comunicaciones telefónicas o de otras formas de comunicación y geolocalización de teléfonos móviles. Desde 2009 se constituyó el PeCERT, equipo de respuesta a incidentes de seguridad cibernéticos (CSIRT) peruano, que ha desempeñado un papel relevante en la atención a los incidentes informáticos. (UNCTAD, 2016 p.61)

\section{Principales barreras al Comercio Electrónico}

En este contexto, tal cual indica CEPAL (2019), hablamos de las barreras al comercio físico de bienes facilitado por medios digitales, y aquellas que obstaculizan el comercio de bienes y servicios transmitidos digitalmente. (p.15). En el mismo sentido, el autor indica que las principales barreras son: el entorno habilitante del comercio electrónico, restricciones técnicas, restricciones de tecnología, requisitos de datos, Derechos del Propiedad Intelectual, restricciones al establecimiento, restricciones fiscales, Contratación Pública. (p.16)

\section{Tabla 8}

Barreras al Comercio Electrónico

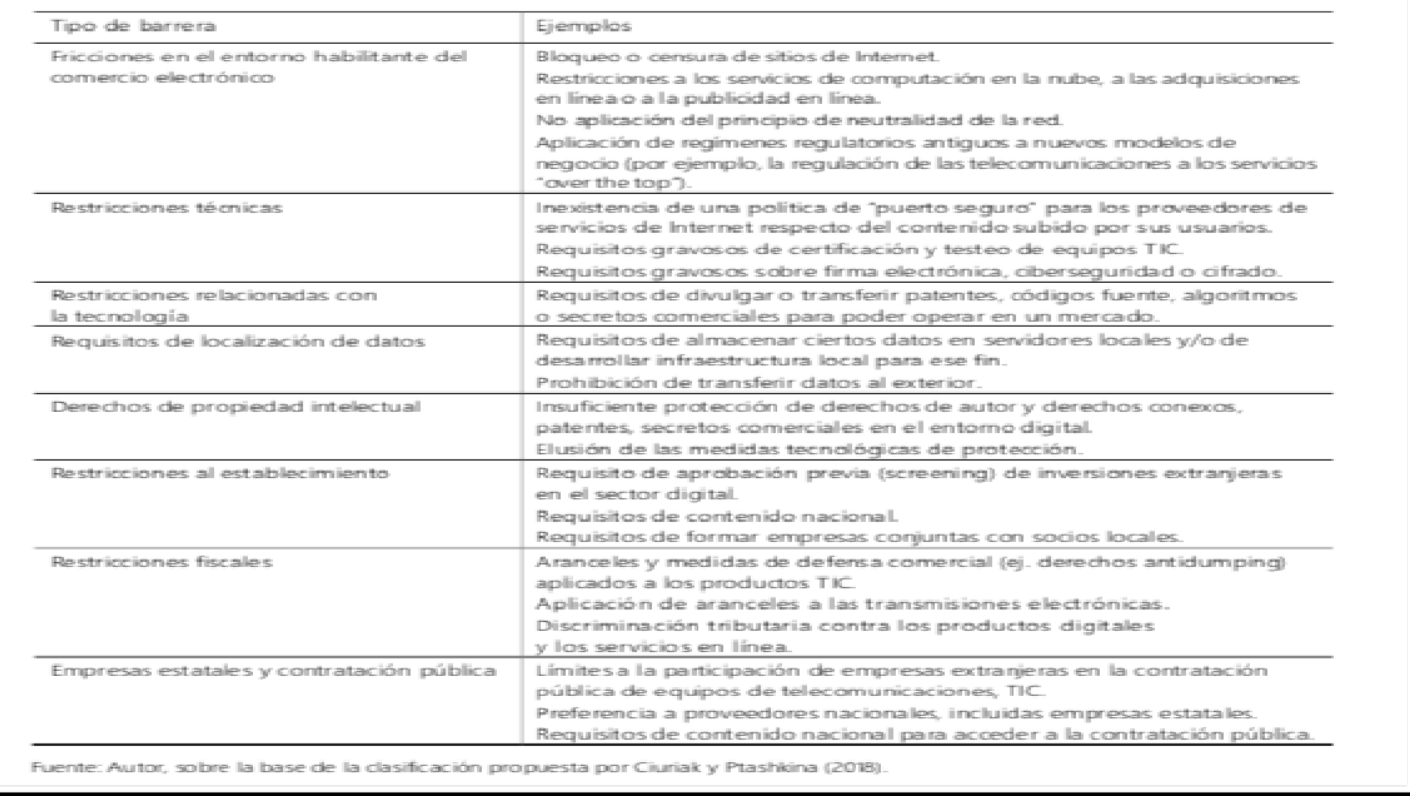

Nota.- Tomado de CEPAL, 2019 (p.16) 


\section{Retos de la Ciberlegislación}

El Comercio Electrónico sigue evolucionando y hoy se presentan nuevos retos a fin de tomar en cuenta las innovaciones de dicho mercado; por tanto, los ámbitos normativos a analizar, de acuerdo a OCDE (2019): La política de consumo, los impuestos, la competencia, el comercio transfronterizo y el medio ambiente. (p.21). Al respecto debemos indicar:

a) Política de consumo: Las leyes de protección al consumidor deberían abarcar las aplicaciones y servicios en línea que se ofrecen de forma "gratuita" a cambio de obtener acceso a los datos personales de un usuario. La Recomendación de la OCDE también indica que las empresas deben tener especial cuidado en la mercadotecnia dirigida a los niños u otros consumidores vulnerables. Asimismo, deben adoptarse disposiciones con el fin de garantizar que los consumidores comprendan los términos y condiciones relativos a la adquisición y utilización de contenidos digitales, y los consumidores deben tener acceso a mecanismos de fácil manejo para resolver las controversias nacionales y transfronterizas en materia de comercio electrónico. La Recomendación también hace un llamado a los gobiernos y a las partes interesadas para que trabajen de manera conjunta con el fin de establecer niveles mínimos de protección al consumidor en todos los mecanismos de pago, dado que el nivel de protección de los pagos puede variar dependiendo del tipo de mecanismo de pago que se utilice. Una mayor confianza en los servicios de pago es esencial para impulsar la participación del consumidor en el comercio electrónico. (OCDE, 2019 p.22)

b) Política impositiva: Uno de los temas actuales constituye la recaudación del impuesto al valor agregado (IVA) o del impuesto sobre bienes y servicios (IBS) en el comercio transfronterizo B2C de bienes, servicios y bienes intangibles. Teniendo en cuenta que es probable que los vendedores digitalizados extranjeros no tengan presencia en el mercado de un consumidor y que esta jurisdicción cuente con recursos limitados para exigirle a un vendedor extranjero que aplique y remita el IVA sobre los servicios y bienes intangibles que se suministran a los consumidores finales en dicha jurisdicción, el resultado es que dichos vendedores sólo pueden cobrar un monto excesivamente bajo o ningún monto correspondiente al IVA sobre dichos suministros. Lo anterior puede tener efectos negativos en los ingresos por concepto de IVA de los países y puede generar condiciones de desigualdad entre los proveedores nacionales y los proveedores extranjeros. . (OCDE, 2019 p.23)

c) Comercio Transfronterizo: Las empresas que se dedican al comercio electrónico transfronterizo se enfrentan a menudo a desafíos derivados de los diferentes entornos normativos en ámbitos como la protección a los consumidores, las leyes y normas en materia de contratos, el etiquetado, los sistemas de logística y distribución, los impuestos y las especificaciones técnicas, tales como la interoperabilidad de los sistemas de pago (OCDE, 2019 p.24)

d) Medio Ambiente: El impacto ambiental del comercio electrónico, el cual, debido al mayor uso de tecnologías digitales como las computadoras y los celulares, también conlleva costos en términos de uso de productos químicos, consumo de electricidad y reciclaje de desechos electrónicos. Un informe reciente de Greenpeace señala que el sector de las TIC consume el $7 \%$ de la producción mundial de electricidad. Es probable que esta proporción se incremente a medida que aumente el comercio electrónico. Del mismo modo, a medida que el comercio electrónico evolucione y los dispositivos con conexión participen cada vez más en las transacciones de comercio electrónico, es probable que las repercusiones ambientales de dichos dispositivos también aumenten. (OCDE, 2019 p.25).

\section{CONCLUSIONES}

El comercio electrónico, se refiere a aquel tipo de transacción entre personas y empresas que involucra la compra, venta o intercambio de productos, bienes o servicios, que se desarrolla a través de redes informáticas, fundamentalmente internet, y cuyo sistema de pago es también es electrónico y las formas de Comercio Electrónico son: B2B, B2C, B2G, C2C y B2E. 
La ciberlegislación involucra tomar en cuenta: a) Las transacciones electrónicas / Firmas electrónicas; b) Delitos Informáticos; c)Protección de Datos; d)Protección del Consumidor; e)Nombres de Dominio; f) Propiedad Intelectual. La región muestra grados disímiles de avance en las distintas dimensiones normativas, particularmente en la protección de la información personal. Respecto al Perú, éste se ha adherido al Convenio del Consejo de Europa sobre la Ciberdelincuencia, de esta manera ha fortalecido la normativa que impulsa el Gobierno electrónico en el país.

Las principales barreras al Comercio Electrónico son: El entorno habilitante del comercio electrónico, restricciones técnicas, restricciones de tecnología, requisitos de datos, Derechos del Propiedad Intelectual, restricciones al establecimiento, restricciones fiscales, Contratación Pública. Siendo el reto en la Ciberlegislación los temas ligados a aspectos de Política impositiva, de Consumo, Comercio Transfronteriza y Medioambiental.

\section{REFERENCIAS}

- Brennen, S., \& Kreiss, D. (23 de 09 de 2014). Culture Digitally. Obtenido de Culture Digitally: http://culturedigitally.org/2014/09/digitalization-and-digitization/

- Blacksip. (2019). El E-Commerce en el Perú 2019. Lima: Blacksip.

- Cámara Peruana de Comercio Electrónico. (2020). Reporte oficial de la Industria del ECommerce en el Perú. Lima: Observatorio E-Commerce.

- Comisión Económica para América Latina y el Caribe. (2019). La regulación del comercio electrónico transfronterizo en los acuerdos comerciales. Santiago de Chile: Naciones Unidas.

- Comisión Económica para América Latina y el Caribe - CEPAL. (2018). Monitoreo de la Agenda Digital para América Latina y el Caribe eLAC2018. Santiago: Naciones Unidas.

- Conferencia de las Naciones Unidas sobre Comercio y Desarrollo - UNCTAD. (2017). Informe sobre la Eocnomia de la Información. Ginebra: Naciones Unidas.

- Conferencia de las Naciones Unidas para el Comercio y Desarrollo (UNCTAD). (2016).Study on the harmonization of cyberlegislation in Latin America. Ginebra: Naciones Unidas.

- Conferencia de las Naciones Unidas para el Comercio y el Desarrollo - UNCTAD. (2019). Digital Economy Report 2019. Ginebra: Naciones Unidas.

- Gutierrez Tovar, E. (2015). Impacto del comercio electrónico en las grandes y medianas empresas de la ciudad de Sogamoso Boyacá, Colombia. Cuadernos Latinoamericanos de Administración, 83-96.

- Helgueros, Y. (2010). Comercio Electrónico como estrategia impulsadora de las exportaciones en México. Revista Internacional de Administración y Finanzas, 81-90.

- Nemat, R. (2011). Taking a look at different types of e-commerce. World Applied Programming, 100-104.

- Ordoñez Moran, A. F., Ordoñez Peña, A. F., \& Victor, A. R. (2016). El comercio electrónico en las empresas. Revista Caribeña de Ciencias Sociales, 1-13.

- Organización Mundial del Comercio - OMC. (2013). El Comercio Electrónico en los países en desarrollo. Ginebra: Organización Mundial del Comercio.

- Organización para la Cooperación y el Desarrollo Económico - OCDE. (2019). Panorama del Comercio Electrónico. Paris: Naciones Unidas.

- Organización para la Cooperación y el Desarrollo Económico - OECD. (2016). Consumer protection en E-Commerce. París: OECD. 